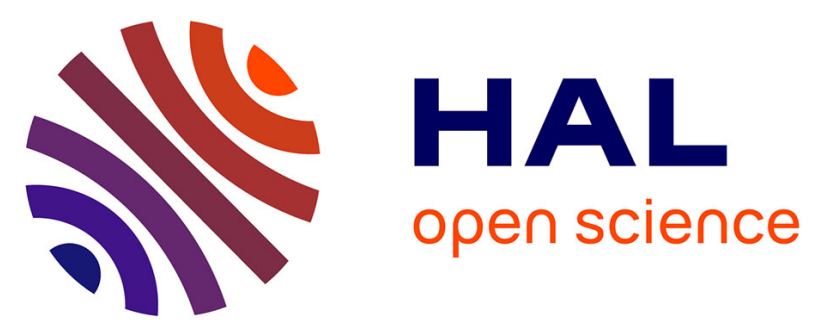

\title{
Insights into carbon nanotube-assisted electro-oxidation of polycyclic aromatic hydrocarbons for mediated bioelectrocatalysis
}

Paulo Henrique M. Buzzetti, Pierre-Yves Blanchard, Emerson Marcelo Girotto, Yuta Nishina, Serge Cosnier, Alan Le Goff, Michael Holzinger

\section{To cite this version:}

Paulo Henrique M. Buzzetti, Pierre-Yves Blanchard, Emerson Marcelo Girotto, Yuta Nishina, Serge Cosnier, et al.. Insights into carbon nanotube-assisted electro-oxidation of polycyclic aromatic hydrocarbons for mediated bioelectrocatalysis. Chemical Communications, 2021, 57 (71), pp.8957-8960. 10.1039/d1cc02958d . hal-03357376

\section{HAL Id: hal-03357376 https://hal.science/hal-03357376}

Submitted on 28 Sep 2021

HAL is a multi-disciplinary open access archive for the deposit and dissemination of scientific research documents, whether they are published or not. The documents may come from teaching and research institutions in France or abroad, or from public or private research centers.
L'archive ouverte pluridisciplinaire HAL, est destinée au dépôt et à la diffusion de documents scientifiques de niveau recherche, publiés ou non, émanant des établissements d'enseignement et de recherche français ou étrangers, des laboratoires publics ou privés. 


\title{
Insights into carbon-nanotube-assisted electrooxidation of polycyclic aromatic hydrocarbons for mediated bioelectrocatalysis
}

\author{
Paulo Henrique M. Buzzetti, ${ }^{a, b}$ Pierre-Yves Blanchard, ${ }^{a}$ Emerson Marcelo Girotto, ${ }^{b}$ Yuta Nishina, ${ }^{c}$ Serge Cosnier, ${ }^{a}$ Alan Le
} Goff, ${ }^{a}$ and Michael Holzinger ${ }^{a} *$

\begin{abstract}
A series of polycyclic aromatics, naphthalene, phenanthrene, perylene, pyrene, 1-pyrenebutyric acid Nhydroxysuccinimide ester (pyrene NHS) and coronene, were immobilized via $\pi$ stacking on carbon nanotube (CNT) electrodes and electro-oxidized in aqueous solutions. The obtained quinones were characterized and evaluated for the mediated electron transfer with FAD dependent glucose dehydrogenase during catalytic glucose oxidation.
\end{abstract}

Polycyclic aromatics and their derivatives are widely used to functionalize carbon nanotubes (CNTs) and graphene ${ }^{1,}$ ${ }^{2}$. Pyrene ${ }^{3}$ and perylene ${ }^{4}$ are within the most famous examples related to easy chemical modification possibilities to attach any desired function. Their ability to form rapidly stable interaction with the pi-system of these carbon materials under ambient condition has the advantage that even sensitive compounds like biomolecules can be immobilized $^{5}$. Other polycyclic aromatic hydrocarbons and derivatives were principally used for solubilization of $\mathrm{CNTs}^{6}$ and graphene ${ }^{7}$ or, in case of coronene, as stacked fluorescent fillers inside CNTs ${ }^{8}$. Unmodified polycyclic aromatic hydrocarbons do not show any electrochemical activity, but they can be electro-oxidized in organic media at high potentials forming oligomers and polymers ${ }^{9,10}$. Barathi et al. studied comprehensively the electro oxidation of anthracene in buffer solutions and demonstrated the formation of the redox active 9,10-anthraquinone ${ }^{11}$. More recently, we reported the formation of electroactive quinones with pyrene on CNTs when electro-oxidized in aqueous media ${ }^{12}$. The obtained pyrenediones showed efficient electron transfers with FAD dependent glucose dehydrogenases (FAD-GDH) and represents a great candidate as mediator in enzymatic biofuel cell anodes. FAD$\mathrm{GDH}$ is a glucose-oxidizing enzyme which has been proposed as a promising alternative to glucose oxidase in biosensors and biofuel cells ${ }^{13,14}$. FAD-GDH has several advantages compared to the commonly used glucose oxidase, such as a tightly-bound FAD cofactor and no activity towards reduction of $\mathrm{O}_{2}$ into $\mathrm{H}_{2} \mathrm{O}_{2}$. The electron transfer between the FAD cofactor and the electrode is quite challenging since this cofactor is deeply embedded inside the protein shell and the maximum distance for direct electron transfer is largely overpassed. Therefore, the only way to obtain efficient electron transfer is the use of redox mediators. Most redox mediators for FAD-GDH are based on osmium complexes ${ }^{15-17}$ and quinones ${ }^{18-20}$. In this work, we extended the CNT-assisted electrooxidation to a range of polycyclic aromatic hydrocarbons from naphthalene (two aromatic rings) to coronene (seven aromatic rings) including pyrene derivatives. We demonstrate that all compounds can be electrooxidized at $1.2 \mathrm{~V}$ vS SCE but with different synthetic yields and redox potentials, suitable or not for mediated electron transfer with FAD-GDH.

The MWCNT electrodes were modified with the polyaromatic hydrocarbons via drop casting as described in the ESI. These electrodes were then electro-oxidized in aqueous electrolyte solution at $\mathrm{pH} 2$ by cycling between -0.2 and 1.2 $\mathrm{V}$ vs SCE at a scan rate of $100 \mathrm{mV} \mathrm{s}^{-1}$. Figure S1 shows the recorded cyclic voltammograms of all studied compounds. The irreversible oxidation observed at $1.1 \mathrm{~V}$ corresponds to the oxidation of each aromatic hydrocarbon ${ }^{12}$. This irreversible oxidation decreases after each scan and in each case, a formation and evolution of a redox signal can be observed. The corresponding $\mathrm{E}^{0}{ }_{\text {app }}$ values (vS SCE and NHE) for each compound are found in Table S1. The intensity of the redox signals can be ascribed to the yield of electro synthesized species. Figure S2 shows the determined yields in combination with the obtained surface coverage as a function of the amount of the deposited hydrocarbon. The highest yields between $8 \%$ and $16 \%$ were obtained with the pyrenes and perylene while naphthalene, phenanthene, and coronene were below 4\%. The optimal surface coverages were obtained for all compounds after deposition of $20 \mu \mathrm{L}$ of a $10 \mathrm{mmol} \mathrm{L}{ }^{-1}$ solution $\left(\mathrm{CH}_{2} \mathrm{Cl}_{2}\right)$. It has to be noted that no clear morphology changes of the CNT electrode during the electrochemical modifications appeared (Figure S3).

The obtained electrodes were then characterized in neutral buffer solution. The CVs in Figure 1 show the redox systems of the adsorbed oxygenated species for each studied aromatic hydrocarbon. While the electro oxidized naphthalene and phenanthrene show respectively identic redox potentials at $\mathrm{E}_{\text {app }}^{0}=-0.17 \mathrm{~V}$ and $-0.19 \mathrm{~V}$ as the commercially available 1,4-naphthoquinone and 9,10-phenanthrenequinone, pyrene, pyrene-NHS, perylene, and coronene show redox potentials at $-0.07 \mathrm{~V},-0.10 \mathrm{~V},-0.14 \mathrm{~V}$, and $-0.08 \mathrm{~V}$ vs SCE, respectively. The electro oxidation of pyrene is perfectly repeatable as reported in our previous work ${ }^{12}$. Its derivative pyrene-NHS has a slightly lower redox potential which can be ascribed to the electron pushing effect of the butyl-NHS function. For naphthalene, phenanthrene, and perylene, a second less pronounced redox system is formed which could partly be identified (see section below). Pyrene and its NHS derivative show clearly higher peak separations $\left(\Delta \mathrm{E}_{\mathrm{p}}\right)$ than the other studied 
compounds. This might be related to the higher electro-oxidation yields resulting in lower diffusion rates. Since the oxidoreduction of quinones is a 2 electrons / 2 protons process (Scheme S1), we observed a linear dependency of the redox potentials on the $\mathrm{pH}$ values which correspond nicely to the thermodynamic slope ${ }^{21}$. The obtained data about electro-oxidation yields, peak separations and $\mathrm{pH}$ dependencies are summarized in Table S1. It should be noted that the presence of a CNTs deposit plays a crucial role since only negligible oxidation yields could be observed with pyrene as reference compound on unmodified glassy carbon electrodes. With the aim to study the properties of these electrogenerated compounds as mediators for the electron transfer with FAD- GDH, stability tests were done by stimulating aging via repeated voltammetric cycling. After 100 cycles between $-0.4 \mathrm{~V}$ and $0.4 \mathrm{~V}$ vs SCE for electro oxidized pyrenes, perylene, and coronene, and between $-0.4 \mathrm{~V}$ and $0.1 \mathrm{~V}$ for electro oxidized phenanthrene, the two studied perylene and pyrene diones showed best stabilities with signal losses below $5 \%$. Naphthoquinone and oxidized coronene also presented good stabilities with signal losses between $10 \%$ and $15 \%$, and almost $30 \%$ of the phenanthrenequinone signal disappeared after cycling. These differences in stabilities might be related to an improved water solubility of the formed hydroquinones or to side reactions during the two electron transfers provoking the loss of electroactivity.
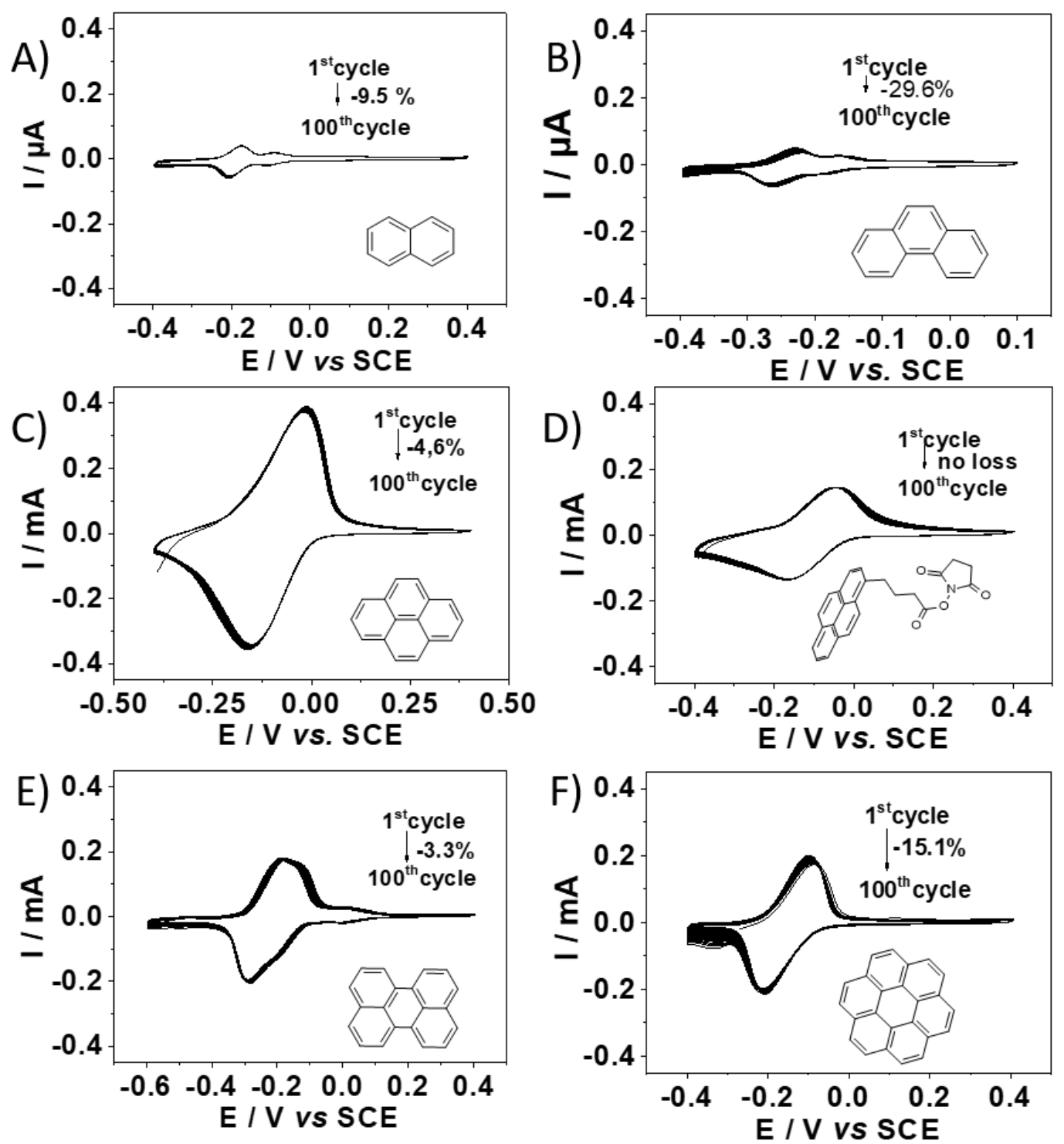

Figure 1: Cyclic voltammograms (100 scans) for the characterization and evaluation of the stability of electro oxidized naphthalene $(A)$, phenanthrene $(B)$, pyrene $(C)$, pyrene-NHS $(D)$, perylene, $(E)$, and coronene $(F)$. The CVs were recorded in phosphate buffer solution $\left(0.1 \mathrm{~mol} \mathrm{~L}^{-1}, \mathrm{pH}\right.$ ) $)$ at a scan rate of $100 \mathrm{mV} \mathrm{s}^{-1}$

To get an idea about the structure of the electroactive species via ${ }^{1} \mathrm{H}$ NMR spectroscopy, $10 \mathrm{MWCNT}$ electrodes were prepared for each polyaromatic hydrocarbon to get sufficient amount of the electro-oxidized compound by immersing and rinsing the resulting electrodes with at total $0.75 \mathrm{~mL}$ of $\mathrm{CDCl}_{3}$. Figure $2 \mathrm{~A}$ shows the spectrum of the electro-oxidized naphthalene. Beside the starting product (protons $\mathrm{Ha}$ and $\mathrm{Hb}$ ) and its impurities (\#), identified on 
the spectrum of purchased naphthalene (not shown), the signals can be assigned to 1,4-naphthoquinone. Other oxides or quinones like 1,2-naphthoquinone could not be resolved.

The spectrum of electro oxidized phenanthrene (Figure 2B) shows in majority the starting material. The additional peaks indicate the presence of 9,10-phenanthrenequinone. The other, unassignable peaks (\#) correspond to impurities in the starting material. Electro-oxidizing pyrene (Figure 2C) led to the two isomers 1,6-pyrenedione and 1,8-pyrenedione. It has to be noted that the starting material pyrene cannot be identified in this spectrum, which is most likely due to the excellent $\pi$-stacking interaction with the CNT sidewall resisting the rinsing steps. The spectrum of the products recovered from the electro-oxidized pyrene-NHS electrodes (Figure 2D) shows in majority the signature of the starting material. The remaining less pronounced peaks can be attributed to 1,8-pyrenedioneNHS and to 1,6-pyrenedione-NHS. Beside the signature of the starting material, the main product after the electro oxidation of perylene (Figure 2E) is 3,10-perylenedione. Less resolved peaks at $7.53 \mathrm{ppm}$ and $6.80 \mathrm{ppm}$ (§) may be assigned to 3,4,9,10-perylenetetrone but noise and partial covering of more pronounced peaks do not allow a clear assignment.

The identified products after electro oxidation of coronene (Figure 2F) are principally the starting product, 1,2coronenedione, and 1,10-coronenedione. However, it remains a certain ambiguity with the assignment of the last compound 1,10-coronenedione. For instance, proton Hh should give a singlet due to the absence of vicinal protons but a triplet is observed. Nonetheless, the interpretation of all spectra was assisted by gradient-selected COSY (gCOSY) spectra and simulation of all possible diones, tetrones, and hexones using the online tool $\mathrm{nmrdb} .0 \mathrm{rg}{ }^{22}$ which led us to conclude for the designated compounds as most likely formed quinones. More NMR data for each compound can be found in the ESI. All modified MWCNT electrodes were then studied towards mediated electron transfer with FAD-GDH immobilized via drop casting. Cyclic voltammograms were recorded between $-0.4 \mathrm{~V}$ and 0.4 $\checkmark$ vs SCE to determine the efficiency of electrocatalytic oxidation of glucose (Figure 3 ).

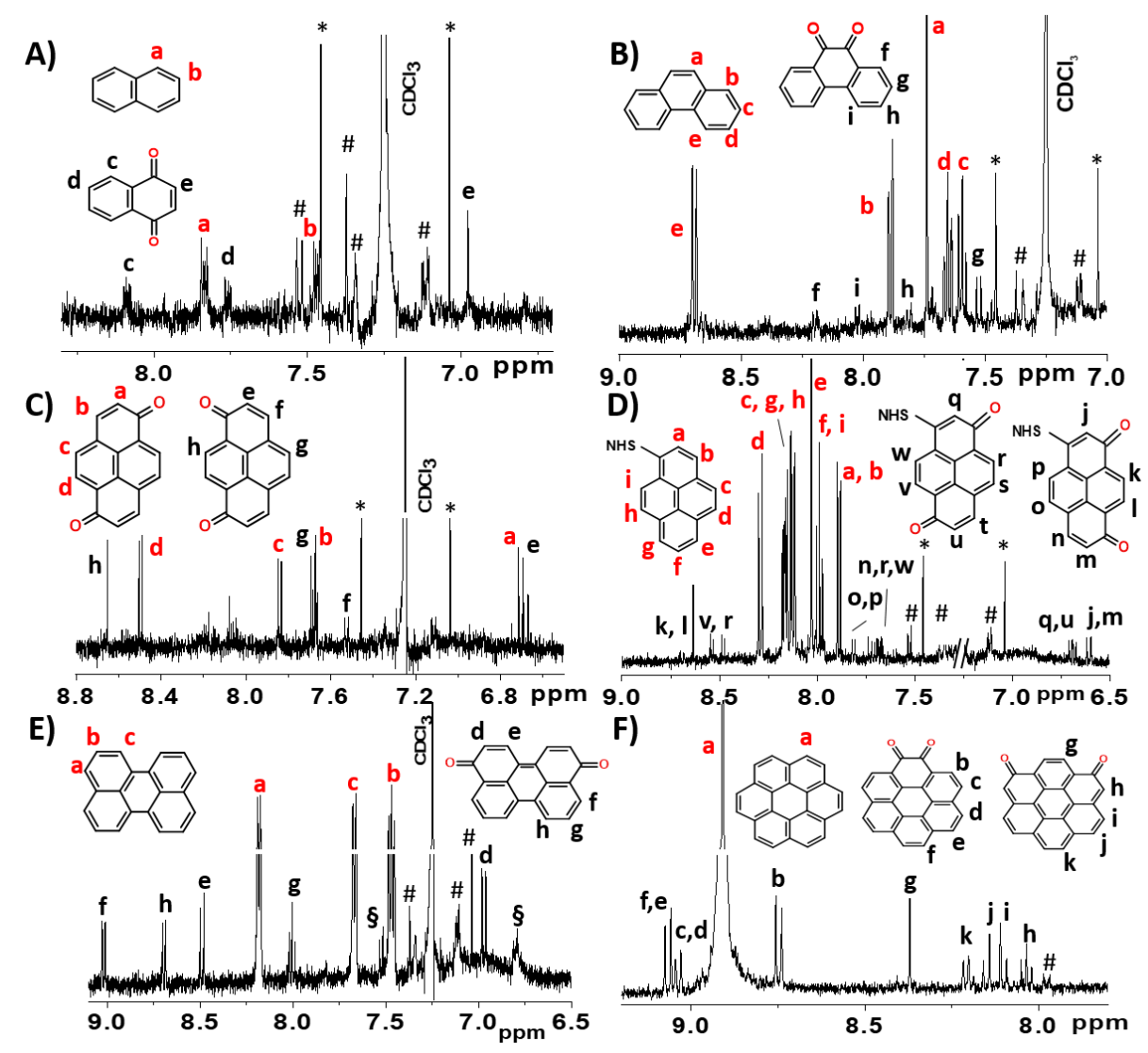

Figure 2: ${ }^{1} \mathrm{H}$ NMR spectra of the recovered oxidized species after electro oxidation of (A) naphthalene, (B) phenanthrene, (C) pyrene, (D) pyrene-NHS, (E) perylene, and (F) coronene. $\left({ }^{*}={ }^{13} \mathrm{C}\right.$ satellite peaks of $\mathrm{CDCl}_{3}$; \# = residues in the starting product)

Electro oxidized naphthalene electrodes provided a catalytic current density of $0.81 \mathrm{~mA} \mathrm{~cm}^{-2}$ at $0.2 \mathrm{~V}$ with an open circuit potential (OCP) of $-0.23 \mathrm{~V}$ (Figure $3 \mathrm{~A}$ ). The $\mathrm{OCP}$, or onset potential, was determined by extrapolation of the linear part of the anodic wave to the potential axis at $0 \mathrm{~A}$. This is consistent with previous studies using 1,4- 
naphthoquinone ${ }^{12}$, taking into account the low electrooxidation yield and the resulting surface coverage. Phenanthrenedione electrodes show a slightly higher current density with $0.9 \mathrm{~mA} \mathrm{~cm}^{-2}$ at $0.2 \mathrm{~V}$ with an onset potential at $-0.24 \mathrm{~V}$ (Figure $3 \mathrm{~B}$ ). These performances are clearly overpassed with pyrenedione electrodes which gave a current density of $7.5 \mathrm{~mA} \mathrm{~cm} \mathrm{~cm}^{-2}$ and an OCP at $-0.14 \mathrm{~V}$ (Figure $3 \mathrm{C}$ ). Interestingly, with similar electro oxidation yield and surface coverage, pyrene-NHS dione provided less than the half of electrocatalytic current density with $3 \mathrm{~mA}$ $\mathrm{cm}^{-2}$ but a slightly lower OCP of $-0.18 \mathrm{~V}$ (Figure 3D). Despite the corresponding redox potential for mediated electron transfers with FAD-GDH, the CVs of both perylenedione and coronenedione did not show any or negligible catalytic currents and are therefore not presented here. We ascribe this incapability to transfer electrons to the size of the compounds and possible steric hindrance to interact with the catalytic site of the enzyme. For the other electrodes, we further stimulated again aging of the electrodes by cycling 100 times to evaluate the stability of electro oxidized compounds for mediated electron transfer. All core compounds lost more than $70 \%$ of their initial current densities with up to $90 \%$ for naphthoquinone. The exception is pyrenedione-NHS which lost less than $13 \%$. This is not surprising since the majority of such losses are related to the desorption of the enzyme ${ }^{12}$. Pyrene-NHS has become a standard linker for the covalent grafting of proteins onto graphene and carbon nanotubes and has been used for two decades ${ }^{3}$.
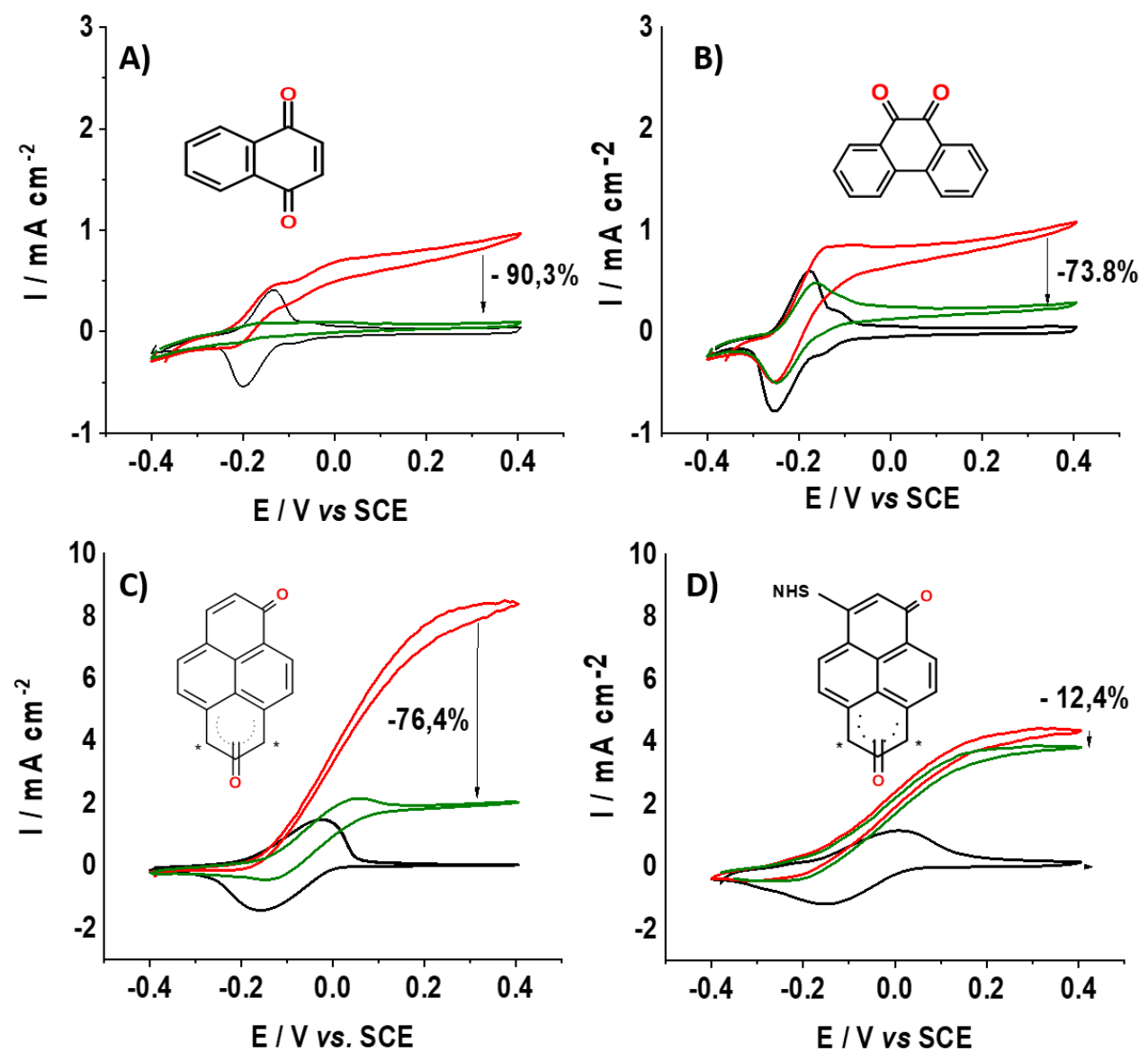

Figure 3: Cyclic voltammograms using FAD GDH modified electrodes with the respective electrooxidized compound. (black) CV before addition of $200 \mathrm{mmolL}^{-1}$ glucose, (red) after glucose addition, (green) 100th cycle for (A) naphthoquinone, (B) phenanthrenequinone, (C) pyrenedione, and (D) pyrene-NHS dione. The CVs were recorded in phosphate buffer solution (0.1 $\mathrm{mol} \mathrm{L}^{-1}, \mathrm{pH}$ 7) at a scan rate of $2 \mathrm{mV} \mathrm{s}^{-1}$

Obviously, electro oxidation of the pyrene units does not affect the activated ester function which forms amides with the enzymes' amine functions and results in clearly enhanced stabilities for mediated electron transfers and thus catalytic current densities. 
These determined performances, however, do not reflect the reality of the capability of these formed quinones for the electron transfer with FAD-GDH since the electro oxidation yield and the resulting surface coverages are different. To harmonize the obtained data and to get a better view about the performances, we plotted the respective redox potentials $\left(E_{1 / 2}\right)$ as a function of the normalized catalytic current densities considering the surface coverage (Figure 4A). With this plot, a clear tendency of electron transfer rates in relation with the redox potential can be observed, where the derivatives of perylene and coronene are excluded due to the size and steric hindrance effects toward FAD-GDH. It appears that the electrochemical properties of pyrenedione allow enhanced electron transfer kinetics at slightly higher but still competitive redox potential for enzymatic biofuel cells. The slightly lower potential of pyrene-NHS matches nicely the trend of the curve but some steric effect of the NHS group vs the access to the prosthetic group of the enzyme can also be imagined. The tendency of higher electron transfer kinetics related to higher overpotentials is perfectly in line with other reports ${ }^{23}$. This mediator was further investigated for its analytical performances in a biosensor configuration (Figure S4). Chronoamperometric measurements at $0.2 \mathrm{~V}$ vs. SCE led to a step wise increase of the catalytic current upon glucose injections until saturation at $200 \mathrm{mmol}^{-1}$. Figure S4B shows the anodic current response of the biosensors as a function of glucose concentration. The sensitivity of this setup, determined by the slope of the linear part of the calibration curve, is $0.44 \mathrm{mAM}^{-1} \mathrm{~cm}^{-2}$. $A$ limit-of-detection of $0.11 \mathrm{mmol}$ was determined. An apparent Michaelis Menten constant of $\mathrm{K}_{\mathrm{M}}^{\mathrm{app}}=23 \mathrm{mmol} \mathrm{L^{-1 }}$ is in good agreement with the report of Tsujimura et al. ${ }^{24}$ The sensor performances are quite satisfying with a good sensitivity and a linear range covering the glucose concentration range of interest for diabetes patients.

To profit from the beneficial properties of pyrenedione in terms of electron transfer efficiency and of pyrene-NHS dione in terms of stability, we used mixtures of these two compounds since the optimal electro oxidation conditions are identic. Figure $4 \mathrm{~B}$ shows the CV of the first and $100^{\text {th }}$ scan of the optimized pyrene/pyrene-NHS mixture (90\% / $10 \%)$. The recorded catalytic current density is $5.9 \mathrm{~mA} \mathrm{~cm}^{-2}$ at $0.2 \mathrm{~V}$ with a relative standard deviation of $15 \%$. This is below the performance of pyrenedione but twice as higher as pyrene-NHS dione only. There is a clearer improvement in terms of stability; after 100 cycles, the loss of electrocatalytic current density is just $13.7 \%$ which is by far more stable than pyrenedione only (> $75 \%)$.

In conclusion, a series of polyaromatic hydrocarbons, immobilized on MWCNT electrodes were electro oxidized in aqueous solution and the obtained quinones were characterized using ${ }^{1} \mathrm{H}$ NMR spectroscopy and cyclic voltammetry. The formed pyrenedione showed to be a more appropriate redox mediator for the electron transfer with the enzyme FAD GDH, giving excellent catalytic current densities at a reasonable half-cell voltage enabling a good cell voltage when combined with an appropriate (bio) cathode. Furthermore, the possibility to electro oxidize its derivative pyrene-NHS, keeping intact the activated ester function, allows to graft covalently the enzyme leading to clearly enhanced stabilities for bioelectrocatalytic oxidation of glucose. In combination with

pyrenedione, glucose-oxidizing bioelectrodes were obtained with high current densities and high operational

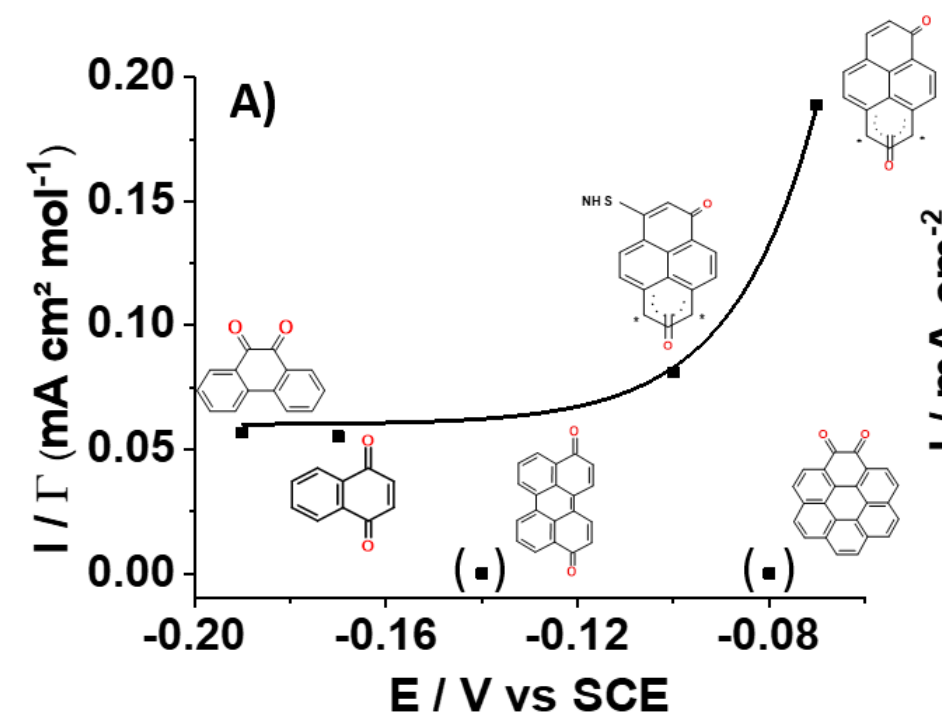

stability.

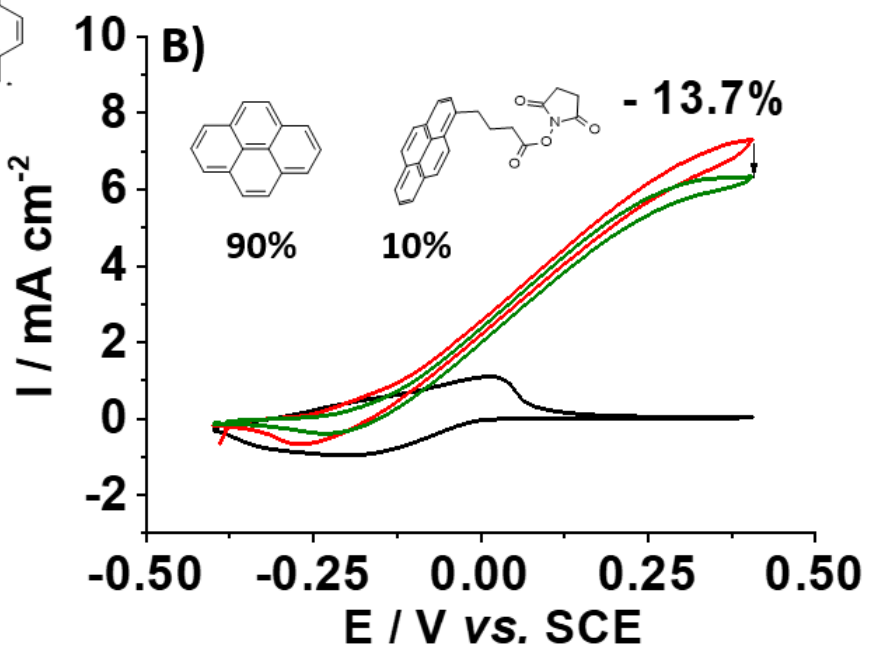

Figure 4: (A) Plot of the surface coverage normalized catalytic current densities as a function of the redox potential of all studied electro oxidized polyaromatic hydrocarbons. (B) Cyclic voltammograms using FAD GDH modified electrodes with a $90 \%-10 \%$ mixture of electro oxidized pyrene and pyrene-NHS. (black) CV before addition of $200 \mathrm{mmolL}^{-1}$ glucose, (red) first cycle after glucose addition, (green) $100^{\text {th }}$ cycle. The CVs were recorded in phosphate buffer solution $\left(0.1 \mathrm{~mol} \mathrm{~L}^{-1}, \mathrm{pH} 7\right)$ at a scan rate of $2 \mathrm{mV} \mathrm{s}^{-1}$

Paulo Buzzetti: Experimentation, Data Curation; Pierre-Yves Blanchard: Review \& Editing; Emerson Marcelo Girotto: Funding acquisition, Review \& Editing; Yuta Nishina: Review \& Editing; Serge Cosnier: Funding acquisition, Review \& 
Editing; Alan Le Goff: Writing, Data Curation; Michael Holzinger: Conceptualization, Supervision, Data Curation, Writing.

There are no conflicts to declare

The authors wish to acknowledge the support from the platform Chimie NanoBio ICMG FR 2607 (PCN-ICMG) and from the LabEx ARCANE (ANR-11-LABX-0003-01 and CBH-EUR-GS, ANR-17-EURE-0003).The authors particularly thank the ANR - JST program, project Mocca-Cell (ANR-15-JTIC-0002-01), and the Institut Carnot PolyNat (CARN 0007-01) for financial support. E.M.G. thanks CNPq for the grants.

1. A. Setaro, J Phys Condens Matter, 2017, 29, 423003.

2. Y. Zhou, Y. Fang and R. P. Ramasamy, Sensors (Basel, Switzerland), 2019, 19, 392.

3. R. J. Chen, Y. Zhang, D. Wang and H. Dai, J. Am. Chem. Soc., 2001, 123, 3838-3839.

4. C. Backes, F. Hauke and A. Hirsch, Adv. Mater., 2011, 23, 2588-2601.

5. $\quad$ N. M. Bardhan, J Mater Res, 2016, 32, 107-127.

6. S. P. Jeong, C. J. Boyle and D. Venkataraman, RSC Adv., 2016, 6, 6107-6110.

7. A. Ghosh, K. V. Rao, S. J. George and C. N. Rao, Chem-Eur J., 2010, 16, 2700-2704.

8. I. V. Anoshkin, A. V. Talyzin, A. G. Nasibulin, A. V. Krasheninnikov, H. Jiang, R. M. Nieminen and E. I. Kauppinen, Chemphyschem, 2014, 15, 1660-1665.

9. J. C. Bachman, R. Kavian, D. J. Graham, D. Y. Kim, S. Noda, D. G. Nocera, Y. Shao-Horn and S. W. Lee, Nat. Commun., 2015, 6, 7040.

10. R. Haddad, M. Holzinger, R. Villalonga, A. Neumann, J. Roots, A. Maaref and S. Cosnier, Carbon, 2011, 49, $2571-2578$.

11. P. Barathi and A. S. Kumar, Chem-Eur J., 2013, 19, 2236-2241.

12. P. Y. Blanchard, P. H. M. Buzzetti, B. Davies, Y. Nedellec, E. M. Girotto, A. J. Gross, A. Le Goff, Y. Nishina, S. Cosnier and M. Holzinger, ChemElectroChem, 2019, 6, 5242-5247.

13. A. Le Goff and M. Holzinger, Sustain. Energ. Fuels, 2018, 2, 2555-2566.

14. M. Rasmussen, S. Abdellaoui and S. D. Minteer, Biosens. Bioelectron., 2016, 76, 91-102.

15. P. Pinyou, A. Ruff, S. Pöller, S. Ma, R. Ludwig and W. Schuhmann, Chem. Eur. J., 2016, 22, 5319-5326.

16. K. Murata, W. Akatsuka, T. Sadakane, A. Matsunaga and S. Tsujimura, Electrochim. Acta, 2014, 136, 537-541.

17. S. Tsujimura, K. Murata and W. Akatsuka, J. Am. Chem. Soc., 2014, 136, 14432-14437.

18. R. D. Milton, D. P. Hickey, S. Abdellaoui, K. Lim, F. Wu, B. Tan and S. D. Minteer, Chem. Sci., 2015, 6, 4867-4875.

19. B. Reuillard, A. Le Goff, C. Agnes, M. Holzinger, A. Zebda, C. Gondran, K. Elouarzaki and S. Cosnier, Phys. Chem. Chem. Phys., 2013, 15, 4892-4896.

20. A. J. Gross, X. Chen, F. Giroud, C. Abreu, A. Le Goff, M. Holzinger and S. Cosnier, ACS Catal., 2017, 7, 4408-4416.

21. M. M. Walczak, D. A. Dryer, D. D. Jacobson, M. G. Foss and N. T. Flynn, J. Chen. Educ., 1997, 74, 1195.

22. D. Banfi and L. Patiny, Chimia, 2008, 62, 280-281.

23. N. Tsuruoka, T. Sadakane, R. Hayashi and S. Tsujimura, Int J. Mol. Sci., 2017, 18, 604.

24. S. Tsujimura, S. Kojima, K. Kano, T. Ikeda, M. Sato, H. Sanada and H. Omura, Biosci. Biotech. Bioch., 2006, 70, 654659. 